\title{
ENUMERAÇÃO, ISOLAMENTO, CARACTERIZAÇÃO E CONTROLE DA MULTIPLICAÇÃO DE Staphylococcus aureus ISOLADO DE LEITE CRU GRANELIZADO
}

\author{
Andressa Susan Silva Brites \\ Bacharel em Ciência e Tecnologia de Alimentos / Tecnóloga em Laticínios / Instituto Federal de Educação, \\ Ciência e Tecnologia Sudeste MG, Campus Rio Pomba / IF Sudeste MG \\ susantla@yahoo.com.br \\ Maurilio Lopes Martins \\ Doutor em Microbiologia / Departamento de Microbiologia / UFV / MG \\ Docente do Departamento de Ciência e Tecnologia de Alimentos / Instituto Federal de Educação, Ciência e \\ Tecnologia Sudeste MG, Campus Rio Pomba / IF Sudeste MG \\ maurilio.martins@ifsudestemg.edu.br
}

\section{Eliane Maurício Furtado Martins}

Doutora em Ciência e Tecnologia de Alimentos / Departamento de Tecnologia de Alimentos / UFV / MG Docente do Departamento de Ciência e Tecnologia de Alimentos / Instituto Federal de Educação, Ciência e Tecnologia Sudeste MG, Campus Rio Pomba / IF Sudeste MG

eliane.martins@ifsudestemg.edu.br

\section{Simone Vilela Talma}

Mestre em Produção Vegetal / Laboratório de Tecnologia de Alimentos / UENF / RJ

Docente do Instituto Federal de Educação, Ciência e Tecnologia de Sergipe Campus Glória / IFS / SE simonevtalma@yahoo.com.br

\section{João Batista Barbosa}

Mestre em Produção Vegetal / Laboratório de Tecnologia de Alimentos / UENF / RJ

Docente do Instituto Federal de Educação, Ciência e Tecnologia de Alagoas Campus Piranhas / IFAL / AL joaotla@yahoo.com.br

\section{Ricardo Augusto Paes Ribeiro}

Tecnólogo em Laticínios / Instituto Federal de Educação, Ciência e Tecnologia Sudeste MG, Campus Rio Pomba / IF Sudeste MG

rpaesribeiro@yahoo.com.br

Recebido: 09 de fevereiro de 2012. Revisado: 15 de abril de 2013. Aceito: 16 de abril de 2013.

Publicado online: 17 de julho de 2013

\section{RESUMO}

A mastite é uma inflamação da glândula mamária causada, principalmente, por micro-organismos, que pode se manifestar na forma clínica ou subclínica. A doença também traz prejuízos para a indústria de laticínios, além de ser um problema para a saúde pública. Os principais agentes infecciosos causadores de mastite são as bactérias, sendo Staphylococcus aureus um dos patógenos de maior incidência. Esta bactéria é encontrada em alguns animais de sangue quente além da pele e mucosas do homem. Apesar do impacto econômico da mastite na cadeia produtiva do leite no Brasil, ainda conhece-se pouco a respeito da epidemiologia da doença nos rebanhos nacionais e faltam estudos de tecnologias alternativas aos métodos tradicionais de uso de antibióticos para o controle da doença. O objetivo desta pesquisa foi enumerar, isolar e caracterizar $S$. aureus a partir de amostras de leite cru refrigerado granelizado da região de Rio Pomba - MG e avaliar o uso de extratos vegetais e própolis para inibir o crescimento deste patógeno. As amostras de leite coletadas nos 
tanques de expansão foram submetidas às análises de enumeração, isolamento e caracterização de $S$. aureus conforme preconizado pela Instrução Normativa $\mathrm{n}^{\circ}$ 62. Constatou-se que $81,1 \%$ das amostras coletadas apresentaram colônias típicas de $S$. aureus. Além disso, a contagem de estafilococos variou de $<1,0 \times 10^{1}$ UFC.mL ${ }^{-1}$ estimada a $1,6 \times 10^{4}$ UFC. $\mathrm{mL}^{-1}$ de leite. Foi avaliado também o efeito inibitório de extratos vegetais e própolis contra esta bactéria sendo que o extrato de alho apresentou maior efeito inibitório contra S. aureus, seguido pelos extratos de própolis, salsa e orégano.

Palavras-chave: Leite cru; Staphylococcus aureus; atividade antimicrobiana.

\begin{abstract}
Mastitis is an inflammation of the mammary gland mainly caused by microorganisms, which can manifest itself in the form of clinical or subclinical. The disease also brings harm to the dairy industry, as well as being a problem for public health. The major infectious agents that cause mastitis are Staphylococcus aureus bacteria, being one of the pathogens of highest incidence. This bacterium is found in some warm-blooded animals in addition to the skin and mucous membranes of humans. Despite the economic impact of mastitis in dairy production chain in Brazil, still know little about the epidemiology of the disease in national herds and there are studies of alternative technologies to traditional methods of use of antibiotics to control disease. The aim of this research was to enumerate, isolate and characterize $S$. aureus from samples of raw milk refrigerated granulated in the region of Rio Pomba- MG and evaluate alternative methods to antibiotics to inhibit the growth of this pathogen. The milk samples collected in the expansion tanks were subjected to analyses of enumeration, isolation and characterization of $S$. aureus as advocated by normative instruction $n^{\circ}$ 62. It was noted that $81.1 \%$ of the collected samples showed typical colonies of S. aureus. In addition, the count of Staphylococcus from $<1,0 \times 10^{1} \mathrm{UFC}_{\mathrm{mL}}^{-1}$ estimated the 1,6 x $10^{4} \mathrm{UFC} . \mathrm{mL}^{-1}$ of milk. Was also assessed the inhibitory effect of plant extracts and of propolis against this bacterium and the garlic extract showed greater inhibitory effect against $S$. aureus, followed by propolis extracts, parsley and oregano.
\end{abstract}

Keywords: Raw milk; Staphylococcus aureus; antimicrobial activity.

\title{
1. INTRODUÇÃO
}

A mastite bovina é uma inflamação do parênquima da glândula mamária que acontece principalmente em resposta à invasão da teta por micro-organismos, embora possa também ser de origem traumática, alérgica ou metabólica (FREITAS et al., 2005).

Estima-se que no Brasil a queda na produção leiteira devido à mastite varia de 12 a $15 \%$, o que representa uma perda de 2,4 bilhões de litros de leite por ano (FONSECA e SANTOS, 2000). Em animais infectados, com mastite, o menor teor de açúcares, gordura, proteínas e minerais e o maior número de proteínas séricas e células somáticas reduzem significativamente a qualidade do leite e derivados, comprometendo o valor nutricional do alimento e sua aceitabilidade pelo consumidor (BRUCKMAIER $e t$ al., 2004; MA et al., 2000).

Os principais agentes infecciosos causadores de mastite são as bactérias, embora a doença também possa ser causada por leveduras e, raramente, por vírus (NATIONAL MASTITIS COUNCIL, 1998). Staphylococcus aureus em casos de mastite bovina é um dos patógenos de maior incidência. Essa bactéria é encontrada no úbere de vacas infectadas, sendo disseminada para quartos mamários não infectados e para animais sadios no momento da ordenha.

No Brasil, $S$. aureus vem sendo isolado de animais apresentando mastite subclínica desde o início da década de 50 e sua predominância sobre os demais agentes da doença já foi comprovada em estudo realizado em diferentes regiões do país (BRITO e BRITO, 1996). Porém, fatores sócio-ambientais como práticas de manejo, localização da propriedade, composição do rebanho e até mesmo as estações do ano afetam a distribuição e incidência dos isolados. 
A presença de S. aureus em quantidade de, aproximadamente, 100.000 UFC.mL ${ }^{-1}$ de leite é suficiente para afetar o consumidor, desde que a estirpe em questão seja capaz de produzir enterotoxina (ZSCHÖCK et al., 2005; CARDOSO et al., 2000).

Antibióticos são eficientes no controle de patógenos contaminantes do leite, porém estas substâncias podem ser encontradas no leite de animais em tratamento, que ao ser consumido pode provocar reações alérgicas em consumidores sensíveis (COSTA, 1999), além de causar outros riscos à saúde humana como desequilíbrio da microbiota intestinal e seleção de bactérias resistentes aos antibióticos no trato digestivo (MANSUR et al., 2003). Na indústria, estes resíduos interferem com a multiplicação de micro-organismos que promovem a coagulação do leite, alterando os produtos derivados (ZSCHÖCK et al., 2005).

Segundo Russell e Mantovani (2002), na busca por métodos mais seguros e saudáveis para o controle do crescimento microbiano, têm aumentado o interesse pelo uso de substâncias alternativas com atividade antimicrobiana. Vários produtos naturais são utilizados há décadas como agentes medicinais e muitos compostos serviram como modelo para a indústria farmacêutica produzir análogos biologicamente ativos, algumas vezes mais eficientes e com menor toxicidade. Dentre estes, óleos essenciais extraídos de vegetais e própolis destacam-se por serem exemplos de compostos sugeridos como alternativa para o uso de antibióticos (ERNANDES E CRUZ, 2008).

O desenvolvimento de metodologias que utilizem extratos vegetais antimicrobianos aquosos é relevante devido a eliminação do uso de substâncias extratoras alcoólicas que podem comprometer o crescimento e atividade microbiana, o que compromete a interpretação dos resultados obtidos.

Os regulamentos para a produção, identidade e qualidade do leite propostos na Instrução Normativa $n^{\circ} 62$ (BRASIL, 2011), preveem a monitorização dos resíduos de antibióticos no leite de todas as propriedades rurais, a ser realizada mensalmente pelos laboratórios credenciados à Rede Brasileira de Laboratórios de Controle de Qualidade do Leite, mas na maioria das vezes este acompanhamento não é realizado e o tempo de carência dos antibióticos não é respeitado pelos produtores de leite.

Partindo dessa realidade, idealizou-se o presente estudo, com o objetivo de enumerar, isolar, caracterizar e estabelecer uma coleção de cultura de $S$. aureus a partir de amostras de leite cru refrigerado granelizado dos tanques de expansão do município de Rio Pomba, MG, e avaliar o uso de extratos vegetais e própolis, alternativos aos antibióticos, para inibir o crescimento desta bactéria e, assim, prevenir ou minimizar os problemas decorrentes da multiplicação de um dos principais agentes causador de mastite bovina no rebanho leiteiro.

\section{METODOLOGIA}

Amostras de leite cru $(200 \mathrm{~mL})$ foram coletadas de 37 tanques de expansão comunitários e individuais do município de Rio Pomba - MG. Essas amostras foram coletadas de forma asséptica, em frascos de $100 \mathrm{~mL}$ estéreis e, imediatamente acondicionadas em caixas isotérmicas e encaminhadas para o Laboratório de Microbiologia do Departamento de Ciência e Tecnologia de Alimentos do Instituto Federal de Educação, Ciência e Tecnologia do Sudeste de Minas Gerais, Câmpus Rio Pomba, onde foram submetidas à enumeração, isolamento e caracterização bioquímica de $S$. aureus de acordo com BRASIL (2003).

A partir da coleção de cultura dos isolados de S. aureus, obtidos dos 37 tanques de expansão, foi determinada à atividade antibacteriana, por meio da utilização de extratos aquosos de alho, própolis, orégano e salsa contra 24 isolados escolhidos aleatoriamente.

\subsection{Preparo do extrato de alho}

As amostras de alho foram submetidas ao processo de retirada das cascas e de trituração em liquidificador. Posteriormente, pesou-se $25 \mathrm{~g}$ do alho triturado e adicionou-se $50 \mathrm{~mL}$ de água destilada. Realizou-se a homogeneização e o frasco foi envolvido com papel pardo para proteger da luz e armazenado 
em temperatura ambiente por 24 horas. Estes procedimentos foram realizados em condições assépticas.

\subsection{Preparo do extrato de própolis}

A amostra de própolis in natura foi armazenada sob refrigeração e protegida da luz. Para obtenção do extrato, foram pesadas $2 \mathrm{~g}$ do própolis em um frasco apropriado e adicionado $25 \mathrm{~mL}$ de água destilada. Essa mistura foi incubada por 2 horas a $95{ }^{\circ} \mathrm{C}$, sendo posteriormente resfriada a temperatura ambiente e o frasco envolvido com papel pardo para proteger da luz e armazenado em temperatura ambiente por 24 horas.

\subsection{Preparo do extrato de orégano}

Foi pesado $25 \mathrm{~g}$ da amostra de orégano seco e adicionado $50 \mathrm{~mL}$ de água destilada. $\mathrm{O}$ frasco utilizado foi levado para banho-maria a $95^{\circ} \mathrm{C}$ por 2 horas. Em seguida, o frasco foi envolvido com papel pardo para proteger da luz e armazenado em temperatura ambiente por 24 horas.

\subsection{Preparo do extrato de salsa}

As amostras de salsa in natura foram lavadas com água corrente e picadas com auxilio de uma faca devidamente higienizada. Posteriormente, foram pesadas $25 \mathrm{~g}$ de salsa, sendo adicionados $50 \mathrm{~mL}$ de água destilada. As amostras foram submetidas ao processo de extração em banho-maria a $95{ }^{\circ} \mathrm{C}$ por 2 horas. Posteriormente, realizou-se a homogeneização e o frasco foi envolvido com papel pardo para proteger da luz e armazenado em temperatura ambiente por 24 horas.

\subsection{Esterilização dos extratos para utilização nos testes de inibição de $S$. aureus}

Após armazenamento por 24 horas protegidos da luz, os extratos obtidos conforme descrito nos itens 2.1. a 2.4. foram filtrados com auxilio de funil e papel de filtro, sendo posteriormente submetidos ao processo de esterilização pelo método de filtração utilizando filtro de $0,22 \mu \mathrm{m}$ e frascos estéreis para coleta dos filtrados.

\subsection{Obtenção dos discos embebidos com os extratos}

Discos de papel esterilizados de $6 \mathrm{~mm}$ de diâmetro foram adicionados assepticamente aos extratos obtidos após esterilização dos mesmos e armazenados por 24 horas protegidos da luz para impregnação dos agentes antimicrobianos nos discos.

\subsection{Avaliação da atividade antimicrobiana dos extratos aquosos de alho, própolis, orégano e salsa contra isolados de $S$. aureus da coleção de cultura}

Para avaliação da atividade antimicrobiana dos extratos aquosos em isolados de $S$. aureus da coleção de cultura, 24 isolados escolhidos aleatoriamente foram ativados em caldo BHI (infusão de cérebro e coração) até atingir densidade óptica 0,5 medida em espectrofotômetro com comprimento de onda de 600 $\mathrm{nm}$. Posteriormente, as culturas foram transferidas com auxílio de swab estéril para placas de Petri contendo Ágar Mueller-Hinton, sendo estas divididas em quadrantes. Os discos obtidos a partir da imersão nos respectivos extratos foram colocados nos quadrantes das placas contendo as culturas, sendo estas incubadas a $37{ }^{\circ} \mathrm{C}$ por 24 horas. Em seguida, foi determinado o efeito antimicrobiano de cada extrato medindo-se o diâmetro em milimetros do halo de inibição do crescimento formado ao redor dos discos em cada placa utilizando-se régua milimetrada.

\section{RESULTADOS E DISCUSSÃO}

Constatou-se que $81,1 \%$ das amostras de leite cru refrigerado granelizado coletadas apresentaram colônias típicas de $S$. aureus, o que indica a alta incidência de leite procedente de animais doentes com mastite (Tabela 1, Tabela 2). 
A contagem de estafilococos variou de $<1,0 \times 10^{1} \mathrm{UFC} \cdot \mathrm{mL}^{-1}$ estimado a $1,6 \times 10^{4} \mathrm{UFC} \cdot \mathrm{mL}^{-1}$ de leite (Tabela 1). A presença de $S$. aureus em quantidade de, aproximadamente, $10^{5} \mathrm{UFC} \cdot \mathrm{mL}^{-1}$ de leite é suficiente para afetar a saúde do consumidor, desde que a estirpe em questão seja capaz de produzir enterotoxina. Como demonstra a Tabela 1 e Tabela 2, dos 67 isolados obtidos neste trabalho, todos foram Gram-positivos, sendo $48 \%, 63 \%$ e $66 \%$, respectivamente, coagulase, catalase e termonuclease positivo, evidenciando a alta probabilidade de ocorrência de $S$. aureus entre os isolados. Estes dados são de grande interesse do ponto de vista de saúde pública, tendo em vista que este micro-organismo apresenta perigo potencial para a saúde humana e dos animais.

Tabela 1: Enumeração e caracterização bioquímica dos isolados de S. aureus

\begin{tabular}{|c|c|c|c|c|c|}
\hline $\begin{array}{l}\text { Número do } \\
\text { tanque } \\
\text { /número do } \\
\text { isolado }\end{array}$ & $\begin{array}{c}\text { Enumeração } \\
\text { de } S . \text { aureus } \\
\left(\text { UFC.mL }^{-1}\right)\end{array}$ & Coagulase & Catalase & $\begin{array}{l}\text { Coloração de Gram } \\
\text { (forma e arranjo) }\end{array}$ & Termonuclease \\
\hline $1 / 1$ & \multirow{3}{*}{$3,4 \times 10^{3}$} & $4+$ & + & $+($ Cocos, estafilococos $)$ & + \\
\hline $1 / 2$ & & $4+$ & + & $+($ Cocos, estafilococos $)$ & + \\
\hline $1 / 3$ & & $4+$ & + & $+($ Cocos, estafilococos $)$ & + \\
\hline $2 / 1$ & \multirow{3}{*}{$<1,0 \times 10^{2}$ (est.) } & - & + & $+($ Cocos, estafilococos $)$ & - \\
\hline $2 / 2$ & & - & + & $+($ Cocos, estafilococos $)$ & - \\
\hline $2 / 3$ & & - & + & $+($ Cocos, estafilococos $)$ & - \\
\hline $3 / 1$ & \multirow{3}{*}{$4,2 \times 10^{2}$ (est.) } & $1+$ & + & $+($ Cocos, estafilococos $)$ & + \\
\hline $3 / 2$ & & $4+$ & + & $+($ Cocos, estafilococos $)$ & + \\
\hline $3 / 3$ & & $1+$ & + & $+($ Cocos, estafilococos $)$ & + \\
\hline $5 / 1$ & $1,0 \times 10^{2}$ (est.) & $4+$ & + & $+($ Cocos, estafilococos $)$ & + \\
\hline $6 / 1$ & \multirow{3}{*}{$5,0 \times 10^{1}$ (est.) } & $1+$ & + & $+($ Cocos, estafilococos $)$ & + \\
\hline $6 / 1$ & & $4+$ & + & $+($ Cocos, estafilococos $)$ & + \\
\hline $6 / 1$ & & $1+$ & + & $+($ Cocos, estafilococos $)$ & + \\
\hline $7 / 1$ & \multirow{3}{*}{$1,5 \times 10^{3}$} & - & + & $+($ Cocos, estafilococos $)$ & - \\
\hline $7 / 2$ & & - & + & $+($ Cocos, estafilococos $)$ & - \\
\hline $7 / 3$ & & $4+$ & + & $+($ Bacilos isolados $)$ & + \\
\hline $8 / 1$ & \multirow{3}{*}{$1,3 \times 10^{3}$} & $4+$ & + & $+($ Cocos, estafilococos $)$ & + \\
\hline $8 / 2$ & & $4+$ & + & $+($ Cocos, estafilococos $)$ & + \\
\hline $8 / 3$ & & $1+$ & + & $+($ Cocos, estafilococos $)$ & - \\
\hline $10 / 1$ & \multirow{3}{*}{$2,5 \times 10^{3}$ (est.) } & $4+$ & + & $+($ Cocos, estafilococos $)$ & + \\
\hline $10 / 2$ & & $4+$ & + & $+($ Cocos, estafilococos $)$ & + \\
\hline $10 / 3$ & & $4+$ & + & $+($ Cocos, estafilococos $)$ & + \\
\hline $11 / 1$ & \multirow{3}{*}{$<1,0 \times 10^{1}$ (est.) } & - & + & $+($ Cocos, estafilococos $)$ & + \\
\hline $11 / 2$ & & $2+$ & + & $+($ Cocos, estafilococos $)$ & - \\
\hline $11 / 3$ & & - & + & $+($ Cocos, estafilococos $)$ & + \\
\hline $12 / 1$ & $1,0 \times 10^{2}$ (est.) & $2+$ & + & $+($ Cocos, estafilococos $)$ & - \\
\hline $14 / 1$ & $2,0 \times 10^{2}$ (est.) & $4+$ & + & $+($ Cocos, estafilococos $)$ & + \\
\hline $15 / 1$ & \multirow{3}{*}{$1,0 \times 10^{2}$ (est.) } & - & + & $+($ Cocos, estafilococos $)$ & + \\
\hline $15 / 2$ & & - & + & $+($ Cocos, estafilococos $)$ & + \\
\hline $15 / 3$ & & $4+$ & + & $+($ Cocos, estafilococos $)$ & + \\
\hline $16 / 1$ & $<1,0 \times 10^{1}$ (est.) & $2+$ & + & $+($ Cocos, estafilococos $)$ & + \\
\hline $17 / 1$ & \multirow{3}{*}{$6,5 \times 10^{2}$ (est.) } & $4+$ & + & $+($ Cocos, estafilococos $)$ & - \\
\hline $17 / 2$ & & $4+$ & + & $+(\operatorname{cocos}$, estafilococos $)$ & + \\
\hline $17 / 3$ & & $4+$ & + & $+($ Cocos, estafilococos $)$ & + \\
\hline
\end{tabular}




\begin{tabular}{|c|c|c|c|c|c|}
\hline $18 / 1$ & \multirow{3}{*}{$<1,0 \times 10^{2}$ (est.) } & - & - & $+($ Cocos, estreptococos $)$ & - \\
\hline $18 / 2$ & & - & + & $+($ Cocos, estafilococos $)$ & - \\
\hline $18 / 3$ & & - & + & $+($ Cocos, estafilococos $)$ & - \\
\hline $19 / 1$ & \multirow{3}{*}{$<1,0 \times 10^{2}$ (est.) } & - & + & $+($ Cocos, estafilococos $)$ & - \\
\hline $19 / 2$ & & - & + & $+($ Cocos, estafilococos $)$ & - \\
\hline $19 / 3$ & & - & + & $+($ Cocos, estafilococos $)$ & - \\
\hline $23 / 1$ & \multirow{3}{*}{$2,8 \times 10^{3}$} & $4+$ & + & $+($ Cocos, estafilococos $)$ & - \\
\hline $23 / 2$ & & $4+$ & + & $+($ Cocos, estafilococos $)$ & + \\
\hline $23 / 3$ & & $3+$ & + & $+($ Cocos, estafilococos $)$ & + \\
\hline $24 / 1$ & $1,5 \times 10^{2}$ (est.) & - & - & $+($ Cocos, estafilococos $)$ & - \\
\hline $25 / 1$ & \multirow{3}{*}{$3,5 \times 10^{3}$} & - & - & $+($ Cocos, estafilococos $)$ & - \\
\hline $25 / 2$ & & $4+$ & + & $+($ Cocos, estafilococos $)$ & + \\
\hline $25 / 3$ & & $4+$ & + & $+($ Cocos, estafilococos $)$ & + \\
\hline $29 / 1$ & \multirow{3}{*}{$3,0 \times 10^{2}$ (est.) } & $4+$ & + & $+($ Cocos, estafilococos $)$ & + \\
\hline $29 / 2$ & & $4+$ & + & $+($ Cocos, estafilococos $)$ & + \\
\hline $29 / 3$ & & $4+$ & + & $+($ Cocos, estafilococos $)$ & + \\
\hline $31 / 1$ & \multirow{3}{*}{$1,6 \times 10^{4}$} & $4+$ & + & $+($ Cocos, estafilococos $)$ & + \\
\hline $31 / 2$ & & $4+$ & + & $+($ Cocos, estafilococos $)$ & + \\
\hline $31 / 3$ & & $2+$ & + & $+($ Cocos, estafilococos $)$ & + \\
\hline $32 / 1$ & \multirow{3}{*}{$2,2 \times 10^{2}$ (est.) } & $3+$ & + & $+($ Cocos, estafilococos) & + \\
\hline $32 / 2$ & & $2+$ & + & $+($ Cocos, estafilococos $)$ & + \\
\hline $32 / 3$ & & - & - & $+($ Cocos, estafilococos $)$ & + \\
\hline $33 / 1$ & \multirow[b]{2}{*}{$2,2 \times 10^{2}$ (est.) } & $4+$ & + & $+($ Cocos, estafilococos $)$ & + \\
\hline $33 / 2$ & & $2+$ & + & $+($ Cocos, estafilococos $)$ & + \\
\hline $34 / 1$ & \multirow{3}{*}{$1,0 \times 10^{3}$} & $4+$ & + & $+($ Cocos, estafilococos $)$ & + \\
\hline $34 / 2$ & & $4+$ & + & $+($ Cocos, estafilococos $)$ & + \\
\hline $34 / 3$ & & $1+$ & + & $+($ Cocos, estafilococos $)$ & + \\
\hline $35 / 1$ & \multirow{3}{*}{$1,0 \times 10^{2}$ ( est.) } & $1+$ & + & $+($ Cocos, estafilococos $)$ & + \\
\hline $35 / 2$ & & $4+$ & + & $+($ Cocos, estafilococos $)$ & + \\
\hline $35 / 3$ & & - & - & $+($ Cocos, estafilococos $)$ & + \\
\hline $36 / 1$ & \multirow{2}{*}{$<1,0 \times 10^{2}$ (est.) } & $1+$ & + & $+($ Cocos, estafilococos) & + \\
\hline $36 / 2$ & & $1+$ & + & + (Cocos, estafilococos) & + \\
\hline $37 / 1$ & \multirow{2}{*}{$<1,0 \times 10^{2}$ (est.) } & $1+$ & + & $+($ Cocos, estafilococos) & + \\
\hline $37 / 2$ & & $1+$ & + & $+($ Cocos, estafilococos $)$ & + \\
\hline
\end{tabular}

Legenda: (est.): estimado; (+): positivo; (-): negativo; (1+): coágulo pequeno e desorganizado; (2+): coágulo pequeno e organizado; (3+): coágulo grande e organizado; (4+): coagulação de todo o conteúdo do tubo, que não se desprendeu quando o tubo foi invertido; Quando a reação de coagulação foi do tipo 3+ e 4+, considerou-se a prova positiva para $S$. aureus.

Tabela 2: Percentual das características típicas das colônias isoladas das amostras de leite cru refrigerado granelizado

\begin{tabular}{lc}
\hline Características das colônias & \% obtido \\
\hline Colônias típicas de S. aureus & 81,1 \\
Gram + & 100,0 \\
Coagulase + & 48,0 \\
Catalase + & 63,0 \\
Termonuclease + & 66,0 \\
\hline
\end{tabular}

A Tabela 3 demonstra a atividade antimicrobiana dos extratos aquosos de salsa, orégano, própolis e alho contra os isolados de $S$. aureus após 24 horas de incubação das placas contendo discos embebidos com os extratos. O extrato de alho apresentou maior efeito inibitório contra os isolados de S. aureus, seguido, pelo extrato de própolis, e os extratos de salsa e orégano apresentaram valores médios iguais. 
De acordo com Fazio, Gonçalves e Hoffmann (2009), estirpes de S. aureus foram sensíveis à ação do extrato de casca de romã. Entretanto, na pesquisa realizada por Pinto et al. (2003), própolis exerceu efeito antibacteriano quando se utilizou extrato etanólico e, em menor proporção, metanólico, contra $S$. aureus, Staphylococcus sp. coagulase negativa e Streptococcus agalactiae, entretanto, este extrato não mostrou capacidade de inibir o crescimento das estirpes Gram-negativas nas concentrações utilizadas. Além disso, foi verificado que estirpes diferentes de uma mesma espécie bacteriana diferiam quanto à sensibilidade à própolis.

Tabela 3: Efeito inibitório dos extratos de salsa, orégano, própolis e alho contra os isolados de S. aureus obtidos do leite cru granelizado da região de Rio Pomba- MG

\begin{tabular}{ccccc}
\hline \multirow{2}{*}{ Isolado } & \multicolumn{4}{c}{ Halo de inibição (cm) } \\
\cline { 2 - 5 } & Salsa & Orégano & Própolis & Alho \\
\hline $1 / 1$ & --- & 0,8 & 0,7 & --- \\
$1 / 2$ & 1,2 & 1,0 & 1,9 & 1,3 \\
$1 / 3$ & 0,7 & 1,8 & 1,7 & 1,2 \\
$3 / 2$ & 1,2 & 1,2 & 1,2 & 2,2 \\
$5 / 1$ & 1,2 & 1,2 & 1,6 & 0,9 \\
$6 / 1$ & 1,2 & 1,2 & 1,0 & 1,1 \\
$8 / 1$ & 1,3 & 1,8 & 1,5 & 1,7 \\
$8 / 2$ & 2,5 & 1,1 & 2,5 & 2,0 \\
$10 / 1$ & 1,2 & 2,1 & 1,5 & 2,7 \\
$10 / 2$ & 1,1 & 1,6 & 1,6 & 1,5 \\
$14 / 1$ & 2,2 & 2,1 & 1,5 & 2,0 \\
$15 / 3$ & 1,3 & 1,1 & 2,1 & 1,7 \\
$17 / 1$ & 1,7 & 1,3 & 1,5 & 1,8 \\
$17 / 2$ & 1,3 & 0,9 & 1,2 & 2,0 \\
$23 / 3$ & 1,5 & 1,2 & --- & 2,3 \\
$25 / 3$ & 1,3 & 1,3 & 0,9 & 1,7 \\
$29 / 1$ & 1,1 & --- & 2,2 & 1,2 \\
$29 / 3$ & 1,3 & 0,9 & 1,0 & 1,3 \\
$32 / 1$ & 1,5 & 2,2 & 2,0 & 1,4 \\
$33 / 1$ & 1,3 & 0,8 & 0,9 & 2,3 \\
$34 / 1$ & 1,3 & 3,0 & 2,1 & 2,2 \\
$33 / 2$ & 1,3 & 1,2 & 1,7 & 2,2 \\
$34 / 2$ & 1,2 & 2,0 & --- & \\
$35 / 2$ & --- & 1,5 & 1,3 & \\
\hline Média & 1,4 & 1,4 & & \\
\hline
\end{tabular}

(---): Não determinado.

\section{CONCLUSÕES}

A frequência de isolamento de $S$. aureus das amostras de leite cru proveniente dos tanques de expansão do município de Rio Pomba- MG foi elevada. Este resultado é de grande interesse do ponto de vista de saúde pública, devido ao fato deste micro-organismo apresentar perigo potencial para a saúde humana e dos animais. Assim, há necessidade de treinamento dos manipuladores, implementação e monitoramento de boas práticas agrícolas e de manejo para melhorar a qualidade do leite da região de Rio Pomba e, consequentemente, minimizar os problemas tecnológicos e diminuir o índice de mastite causada por S. aureus.

Os resultados obtidos neste estudo permitem demonstrar que os extratos utilizados apresentam potencial de serem utilizados na formulação de antimicrobianos. Entretanto, são necessários maiores estudos sobre a aplicação, purificação, concentração, modo de ação e estabilização dos mesmos. 


\section{REFERÊNCIAS BIBLIOGRÁFICAS}

BRASIL. Ministério da Agricultura, Pecuária e Abastecimento. Departamento de Inspeção de Produtos de Origem Animal. Instrução Normativa $n^{\circ} 62$, de 26 de agosto de 2003. Métodos analíticos oficiais para análises microbiológicas para controle de produtos de origem animal e água. Diário Oficial da república Federativa do Brasil, Brasília, DF, 18 set, 2003.

BRASIL. Ministério da Agricultura, Pecuária e Abastecimento. Departamento de Inspeção de Produtos de origem Animal. Instrução Normativa ${ }^{\circ} 62$, de 29 de dezembro de 2011. Aprova o Regulamento Técnico de Produção, Identidade e Qualidade do Leite tipo A, o Regulamento Técnico de Identidade e Qualidade de Leite Cru Refrigerado, Leite Pasteurizado e o Regulamento Técnico da Coleta de Leite Cru Refrigerado e seu Transporte a Granel. Diário Oficial da República Federativa do Brasil. Brasília, 30 dez. 2011.

BRITO, M. A. V. P.; BRITO, J. R. F. Produção científica brasileira sobre mastite bovina. In: BRITO, J. R. F.; BRESSAN, M. (Eds.). Controle integrado da mastite bovina. Juiz de Fora: Embrapa-CNPGL, 1996, p. 68-96.

BRUCKMAIER, R. M.; ONTSOUKA, C. E.; BLUM, J. W. Fractionized milk composition in dairy cows with subclinical mastitis. Veterinární Medicína, v. 49, p. 283-290, 2004.

CARDOSO, H. F. T.; CARMO, L. S.; SILVA, N. Detecção da toxina - 1 da síndrome do choque tóxico em amostras de Staphylococcus aureus isoladas de mastite bovina. Arquivos Brasileiros de Medicina Veterinária e Zootecnia, v. 52, p. 7-10, 2000.

COSTA, E. O. Uso de antimicrobianos na mastite. In: SPINOSA, H. S.; GÓRNIAK, S. L., BERNADI, M. M. (Eds). Farmacologia aplicada à medicina veterinária. 2. ed. Rio de Janeiro: Guanabara Koogan, 1999, p. 422-434.

ERNANDES, F. M. P. G.; CRUZ, C. H. G. Atividade antimicrobiana de extratos de algumas plantas comumente consumidas no Brasil. Higiene Alimentar, v. 22, p. 66-71, 2008.

FAZIO, M. L.; GONÇALVES, T. M. V.; HOFFMANN, F. L. Determinação da atividade antimicrobiana de romã (Punica granatum L.). Higiene Alimentar, v. 23, p. 54-56, 2009.

FONSECA, L. F. L.; SANTOS, M. V. Qualidade do leite e controle da mastite. São Paulo: Lemos Editorial. 2000, 175p.

FREITAS, M. F. L.; PINHEIRO JÚNIOR, J. W.; STAMFORD, T. L. M.; RABELO, S. S. A.; SILVA, D. R.; SILVEIRA FILHO, V. M.; SANTOS, F. G. B.; SENA, M. J.; MOTA, R. A. Perfil de sensibilidade antimicrobiana in vitro de Staphylococcus coagulase positivos isolados de leite de vacas com mastite no agreste do estado de Pernambuco. Arquivos do Instituto Biológico, v. 72, p. 171-177, 2005.

MA, Y.; RYAN, C.; BARBANO, D. M.; GALTON, D. M.; RUDAN, M. A.; BOOR, K. J. Effects of somatic cell count on quality and shelf-life of pasteurized fluid milk. Journal of Dairy Science, v. 83, p. 264-274, 2000.

MANSUR, P. U.; FOLLY, M. M.; CARLOS, L. A.; ARAÚJO, F. M.; GAI, Z. T.; TEIXIERA, G. N. Avaliação do período de persistência do antibiótico cloxacilina no leite de vacas com mastite subclínica.

Higiene Alimenentar, v. 17, p. 106-107, 2003.

NATIONAL MASTITIS COUNCIL. Current concepts of bovine mastitis. 4. ed. Madison, 1998, 64p.

PINTO, M. S.; FARIA, J. E.; CASSINI, S. T. A.; MESSAGE, D.; PEREIRA, C. S. Curva de sobrevivência de bactérias isoladas do leite de vacas com mastite a três extratos etanólicos de própolis. Revista Brasileira de Ciência Veterinária, v. 10, p. 21-26, 2003. 
RUSSELL, J. B.; MANTOVANI, H. C. The bacteriocins of ruminal bacteria and their potential as alternative to antibiotics. Journal of Molecular Microbiology and Biotechnology, v. 4, p. 347-355, 2002.

ZSCHÖCK, M.; BÄRBEL, K.; WOLTER, W.; HAMANN, H. P.; LÄMMLER, C. Pattern of enterotoxin genes seg, seh, sei and sej positive Staphylococcus aureus isolated from bovine mastitis. Veterinary Microbiology, v. 108, p. 243-249, 2005. 